\title{
Nutrition in Cancer Prevention and Treatment
}

\author{
Edith N Fombang* \\ National School of Agro-Industrial Sciences, University of Ngaoundere, Cameroon
}

Submission: September 9, 2017; Published: September 14, 2017

*Corresponding author: Edith N Fombang, National School of Agro-Industrial Sciences, ENSAI, University of Ngaoundere, Cameroon P.0 Box 455, Ngaoundere, Adamawa Region, Cameroon Email: edfombang@yahoo.fr

\section{Nutrition to Prevent Cancer}

Good nutrition and healthy eating habits are important not only to prevent cancer but equally during cancer treatment to improve patient's response to treatment.

Most cancers can be prevented if people adopt appropriate eating habits and healthy lifestyles (i.e maintain a healthy weight and practice regular physical activity). Amongst the foods recommended for the prevention of cancers we have fruits and vegetables, whole grains, nuts and legumes. A diet that is abundant in these foods and is low in red and processed meats is beneficial in the prevention of cancer. These foods provide vitamins, minerals and naturally-occurring protective plant phytochemicals that can help to defend the body against cancer. These protective substances help in diffusing potential carcinogens, eliminate toxins that may lead to cancer, facilitate cellular repair, stagnate the growth of cancer cells and induce cell apoptosis.

The anticancer efficacy of phytochemicals in particular has been attributed to their antioxidant, anti-proliferative, and apoptotic activities. They do this through their ability to modulate multiple biological mechanisms involved in cancer initiation and progression as well as targeting metabolic pathways important in curtailing cancer invasion and metastasis. Thus antioxidants have the potential to stimulate the immune system, slow the growth rate of cancer cells, and prevent DNA damage that can lead to cancer [1-2].

Consumption of soy foods has also been correlated with low rates of breast, colon and prostate cancer amongst others. Soybeans are said contain a number of anti-carcinogens. Amongst its protective effects is the suppression of the growth of cancer cells. Soy isoflavones have been shown to target major epigenetic mechanisms regulating gene expression including DNA methylation; affect cell proliferation, migration, invasion and metastasis formation [3].

\section{Nutrition During Cancer Treatment}

Healthy eating habits and good nutrition can help patients deal with the effects of cancer and its treatment.
Cancer treatments are more effective when the patient is well nourished and gets enough calories and protein in the diet. Cancer treatment (chemotherapy, radiation therapy and surgery) can place a lot of nutritional demand on the body because the side effects of these treatments can affect ones eating habits and consequently ones nutritional status. Some side effects of cancer treatment include nausea, vomiting, fatigue, appetite loss, weight loss, bowel changes, mouth and throat sores, constipation, diarrhea and weakening of the immune system. The main nutritional goals during this period of treatment are maintaining a healthy weight and controlling the side effects of treatment. Therefore, eating healthy foods that supply the body with calories and nutrients for energy, repair, recovery, and healing are essential to achieving this goal. In this regard, adequate calories and proteins are needed for the body to repair itself [4].

A healthy eating pattern during treatment includes plenty of vegetables and fruit, moderate amounts of whole grains, and plant protein sources like nuts, beans, lentils, along with modest portions of fish, poultry, lean meats, and nonfat or lowfat dairy foods. Cancer patients who have an immune system compromised by cancer treatment should avoid foods that can cause further harm like unpasteurized dairy products, raw fish and meat or foods that are undercooked. Consumption of antioxidant rich foods and phytochemicals during treatment can protect normal cells against free radical during treatment thus reducing the damage caused by chemotherapy and radiation therapy and reduce radiation induced side effects $[2,4]$.

Inadequate nutrition can keep the body from healing both from the cancer and the effect of its treatment and could in some instances result in malnutrition and increased toxicity. Cancer-associated malnutrition is common in cancer patients and is the leading cause of morbidity and mortality, especially in advanced stages of the disease. Factors implicated in the development of under nutrition in cancer patients are: reduced dietary intake, malabsorption and altered metabolism. These factors can result from the host response to the cancer itself, 
the anti-cancer therapy or the effects of the cancer itself on metabolism. These detrimental factors can act as a single cause or combination leading to a greater risk of under nutrition [5].

\section{References}

1. Aleksandra Niedzwiecki, MohdWaheed Roomi, Tatiana Kalinovsky and Matthias Rath (2016) Anticancer Efficacy of Polyphenols and Their Combinations. Nutrients 8(9): 552.

2. Yue Zhou, JieZheng, Ya Li, Dong-Ping Xu, Sha Li, et al. (2016) Natural Polyphenols for Prevention and Treatment of Cancer. Nutrients 8(8) : 515 .

This work is licensed under Creative Commons Attribution 4.0 License

DOI: $10.19080 /$ NFSIJ.2017.03.555607
3. Maria Pudenz, Kevin Roth and Clarissa Gerhauser (2014) Impact of Soy Isoflavones on the Epigenome in Cancer Prevention. Nutrients 6(10): 4218-4272.

4. Hui-Ping Chang, Lee-Yan Sheen, Yen-Ping Lei (2015) The protective role of carotenoids and polyphenols in patients with head and neck cancer. J Chin Med Assoc 78(2): 89-95.

5. Taus Marina, Debora Busni, Daniele Fumelli, Albano Nicolai (2014) Pathophysiology of malnutrition and cachexia in cancer patients. Nutritional Therapy \& Metabolism 32(1): 10-16.

\section{Your next submission with Juniper Publishers} will reach you the below assets

- Quality Editorial service

- Swift Peer Review

- Reprints availability

- E-prints Service

- Manuscript Podcast for convenient understanding

- Global attainment for your research

- Manuscript accessibility in different formats ( Pdf, E-pub, Full Text, Audio)

- Unceasing customer service

Track the below URL for one-step submission https://juniperpublishers.com/online-submission.php 